\title{
OUTWARD HABITS AND ENVIRONMENTAL QUALITY IN AN OVERLAPPING GENERATIONS MODEL
}

\author{
Fatma Safi \\ Department of Economics, Faculty of Economics and Management, University of Sfax, Sfax, \\ Tunisia \\ fatmasafi@yahoo.fr
}

\begin{abstract}
Outward habit formation affects consumption decisions. Since consumption displays a negative environmental externality, outward habits has as well an (adverse) effect on the environment. This research paper centers around the theoretical linkage between the combination of both externalities (environmental deterioration and outward habits). The objective of this study is to examine the impacts of outward habits on the state of the environment in the context of an overlapping generations economy. In our study, environmental quality is a public good negatively affected by consumption activity and positively affected by maintenance investment. With outward habit formation, the build-up level of average past consumption in the economy at large influences the current utility of an individual consumer. Thus, individuals draw utility not only from their own level of current consumption, but also from its level relative to the average consumption in the economy. How does outward habit influence the state of the environment? We analyze this question using an overlapping generations model with outward habit and environmental quality in the utility function. In steady state equilibrium allocation, we show that whether outward habits are destructive to the environment depends on the degrees of outward habit formation and the size of the economy.
\end{abstract}

Keywords: outward habits, overlapping generations, environmental quality, consumption, externalities

JEL Classification: D62, D91, E21, Q50

\section{Introduction}

The major issue related to environmental preservation is that agents fail to internalize the long-term consequences of their decisions on the environment. An agent's present actions generate outcomes that outlive it. The intergenerational feature characterizing the environmental problems rationalizes the use of the overlapping generations model (OLG) developed by Allais (1947) and Diamond (1965) in a dynamic setting (see, for instance, John and Pecchenino, 1994; Jouvet, 1998; Ono and Maeda, 2001).

In the present analysis, we go along this line of the literature though we bring in another intergenerational externality under the specification of outward habits. On economic growth, several researches employed the traditional approach which highlights the supply-side of the economy and supposes that agent has exogenous preferences that are not dependent

Cite as:

Safi, F., 2021. Outward Habits and Environmental Quality in an Overlapping Generations Model. Oradea Journal of Business and Economics, 6(1), pp. 42-50. http://doi.org/10.47535/19910jbe120 
of social interactions. The relative position of agents in society gives reason to take into consideration unconventional economic models, involving in particular those with endogenous preferences and relative utility. Psychologists have often considered that people feel happiness by doing well compared with some reference group. In economic language, this reflection is identified as the desire to keep up with the Joneses and the agent is "outward-looking" (de la Croix, 1996; de la Croix and Michel, 1999). Indeed, Clark and Oswald (1996) or Ferrer-iCarbonell (2005) among others, display that utility relies not only on current consumption but also on some reference point. Furthermore, as stated by Becker (1992), household behavior is influenced by inherited tastes that are transmitted from parents to children.

Social concern is linked to the relative position of an agent in a society and can be represented in various specifications: social recognition, self-respect, honor, esteem, social standing, and prestige. Agents seek not only for tangible incentive regarding payoffs but also for social incentives. For instance, a car might not only be purchased for its usefulness but also to get status. Traditionally, a public good fails to be provided privately because of its feature of being non-rival and non-excludable. Selfish agents have disincentive to contribute, and may free ride on its supply. Nevertheless, from a behavioral economics point of view, other-regarding preferences and self-identity may generate intentional contributions to an environmental public good. These incentives are not only crucial for just social problems but they can in general affect consumer decisions as regards purchasing and exploiting goods and services with environmental effects.

The present paper goes along with models that have incorporated social concern effects in dynamic models dealing with environmental issues. We choose to study theoretically the link between outward habits and the environment through environmentally harmful consumption affected by status seeking behaviour using a constant relative risk aversion (CRRA) utility function. We find that the relationship between outward habits and the environment may be either positive or negative depending on the degrees of status seeking and the size of the economy.

The remainder of this paper is organized as follows. Section 2 contains a theoretical background. Section 3 develops the model. Section 4 outlines the optimization problem. Section 5 characterizes the steady state. In Section 6, we illustrate the main results. Section 7 concludes.

\section{Theoretical background}

Numerous recent researches revealed that agents are concerned about their relative positions in society and suggest employing these models in environmental researches. Howarth (1996) analyses theoretically the link between social position, consumption levels and environmental degradation. Social position has a positive impact on consumption. To attain social optimum, consumption taxes are required along with environmental taxes. As to environmental policy, this signifies that Pigovian taxes must be regulated upwards. Brekke et al. (2002) review the Hirsch (1976) hypothesis, i.e., status concern raises consumption at the cost of environmental norms. They find that this only occurs when status and non-status goods are poor substitutes.

Wendner $(2003,2005)$ examine the relationship between status impacts and the design of optimal environmental policies. These papers suggest that status desire causes environmental degradation.

Howarth (2006) includes relative consumption impacts in a calibrated model of optimal carbon dioxide abatement and realizes that the optimal level of abatement is substantially larger when these impacts are taken into consideration. 
Katayama and Long (2010) examine the relationship between status seeking and the exploitation of a common-property exhaustible resource. They point out that the degree of status-consciousness has significant effects on the Markov-perfect Nash equilibrium. A higher degree of status-consciousness leads to higher excessive consumption, and lower capital accumulation.

In a study of electricity framework, Ek and Söderholm (2008) consider the effect of wanting to sustain a positive self-image as a socially responsible person on the demand for "green" electricity. They realize that a choice between green and other electricity is decided not only by economic reasons but also by the existence of social concern behavior.

Rauscher (2006) analyzes theoretically the impact of forcing an emission tax on voluntary cooperative behavior. He shows that behavior stimulated by social motives and intrinsic motivation may be weakened by the implementation of a standard policy instrument formerly intended to affect self-interested agents.

In an economy with private consumption goods, positional preferences induce a welfare loss, which can be worsened if public negative externalities are considered (Long and Wang, 2009).

Aronsson and Johansson-Stenman (2014) explore the optimal provision of state variable public goods by taking global climate as example in a setting where individuals are concerned by relative consumption. They conclude that the extent to which the conventional rules for provision of state-variable public goods should be modified rely upon the strength of the relative concerns, but also on the preference elicitation format.

Bouché (2017) focuses on the analysis of the optimal allocation and its decentralization by means of an appropriate tax policy. The author indicates that a sufficiently high social discount factor is needed to prevent possible local oscillations. Furthermore, investment should either be subsidized or taxed according to the magnitude of both externalities (environmental deterioration and aspirations) while maintenance expenditure should always be subsidized.

In an OLG framework, Bouché and de Migel (2019a) study optimal fiscal policies where preferences display aspirations in consumption and environmental quality as well as habit formation. They highlight the second-best policies when the government needs to finance a particular stream of public expenditures by using distortionary taxes. They obtain necessary and sufficient conditions under which the competitive equilibrium is characterized by levels of capital and environmental quality that are too small and a level of labor supply that is too large.

Bouché and de Migel (2019b) investigate the consequences of assuming that the intensity of aspirations is endogenous. According to empirical evidence, consumption aspirations reduce with capital accumulation while environmental one's increase. They demonstrate that such a change in the intensity of aspirations engenders a U-shaped relationship between capital accumulation and environmental quality.

\section{The model}

We assume a perfectly competitive overlapping generations economy where economic activity is operated over infinite discrete time. Agents live two periods, youth and old age. We define by generation $t$ the cohort of agents born at $t$, with $t=1 ; 2 ; 3 ; \ldots$. We consider that population is constant and each generation consists of a single representative individual.

Due to the presence of outward habits, individuals derive utility not only from their absolute consumption levels and from environmental quality, but also from the status attained by consuming at above-average levels. Let $c_{t}^{1}$ denote consumption of generation $t$ in youth, $c_{t+1}^{2}$ consumption of generation $t$ in old age and $E_{t+1}$ environmental quality in period $t+1$. 
We introduce other-regarding habits in consumption following the work of Wendner (2005). The variable $\tilde{c}_{t}^{1}$ defines effective consumption of a single individual in the first period of life:

$$
\tilde{c}_{t}^{1} \equiv c_{t}^{1}-\gamma C_{t}
$$

The parameter $\gamma$ expresses the desire of households for status and it is assumed to have a positive value $\gamma>0$, which characterizes the consumption of non-durable goods and services. The higher $y$ is, the more young individuals care for status and for the consumption level of their peers. $C_{t}$ is the average consumption across all individuals such that;

$$
C_{t} \equiv\left(\sum_{i}\left(c_{t}^{1}\right)^{i}+\sum_{j}\left(c_{t}^{2}\right)^{j}\right) /\left(L_{t}+L_{t-1}\right)=\left(\sum_{i}\left(c_{t}^{1}\right)^{i}+\sum_{j}\left(c_{t}^{2}\right)^{j}\right) / 2 L
$$

Each young generation consists of $L_{t}$ identical individuals. For the purposes of simplicity, we suppose a zero growth rate of the population. I.e., $L_{t}=L$ and each young and old generation consists of $L$ individuals. The superscripts $i$ and $j$ represent respectively a single individual from young and old generations. In aggregate, if all individuals behave the same way,

$$
C_{t} \equiv\left(L_{t} c_{t}^{1}+L_{t-1} c_{t}^{2}\right) /\left(L_{t}+L_{t-1}\right)=\left(c_{t}^{1}+c_{t}^{2}\right) / 2
$$

Individuals take $C_{t}$ as given. Each person's status rises with his own consumption, but reduces with the average consumption of society.

Variable $\tilde{c}_{t+1}^{2}$ denotes effective consumption of an individual born in $t$ in the second period of life:

$$
\tilde{c}_{t+1}^{2} \equiv c_{t+1}^{2}-\gamma C_{t+1}
$$

Substituting equation (3) into (1) gives

$$
\tilde{c}_{t}^{1}=\frac{(2-\gamma) c_{t}^{1}-\gamma c_{t}^{2}}{2}
$$

Similarly, substituting equation (3) into (4) gives

$$
\tilde{c}_{t+1}^{2}=\frac{(2-\gamma) c_{t+1}^{2}-\gamma c_{t+1}^{1}}{2}
$$

Assuming that preferences over consumption are additively separable over time and in each period; consumption is estimated by a CRRA utility function is a general current practice in macroeconomics. The isoelastic utility function is a function that presents a constant elasticity, i.e., has a constant elasticity coefficient. This utilityis defined as

$$
U_{t}=\frac{\left(\tilde{c}_{t}^{1}\right)^{1-\varepsilon}-1}{1-\varepsilon}+\frac{\left(\tilde{c}_{t+1}^{2}\right)^{1-\varepsilon}-1}{1-\varepsilon}+\frac{\left(E_{t+1}\right)^{1-\varepsilon}-1}{1-\varepsilon}
$$

where the coefficient $\varepsilon>0$ represents the magnitude of elasticity of marginal utility with respect to consumption or environmental quality and it is the coefficient of relative risk aversion. The individual's utility $U$ is derived from consumption and environmental quality in first and second periods. We suppose $U($.$) is strictly increasing, strictly concave,$ homogeneous, and twice continuously differentiable where $U_{\tilde{c}_{t}^{1}}^{\prime}>0 ; U_{\tilde{c}_{t+1}^{2}}^{\prime}>0 ; U_{E_{t}}^{\prime}>0$; $U_{E_{t+1}}^{\prime}>0$ and $U_{\tilde{c}_{t}^{1}}^{\prime}<0 ; U_{\tilde{c}_{t+1}^{2}}^{\prime}<0 ; U_{E_{t}}^{\prime \prime}<0 ; U_{E_{t+1}}^{\prime \prime}<0$. 
Variable $E$ denotes environmental quality, which is an intergenerational public good. As in John and Pecchenino (1994) the index of environmental quality evolves according to the equation:

$$
E_{t+1}=E_{t}-\beta\left(\sum_{i=1}^{L}\left(c_{t}^{1}\right)^{i}+\sum_{j=1}^{L}\left(c_{t}^{2}\right)^{j}\right)+\delta \sum_{i=1}^{L}\left(m_{t}\right)^{i}
$$

$E_{t}$ is the environment quality in period $t, E_{t+1}$ is the environment quality in period $t+1$, $\beta>0$ stands for the degradation of the environment and $\delta>\mathbf{O}$ is the environmental improvement due to the actions of the young at $t$ and $m_{t}$ is the aggregate maintenance investment made for the environment in period $t$. The maintenance activity in period $t$ is conducted by generation $t$ since this generation can enjoy the improved environmental quality in its old age.

Each generation is endowed with $w$ units of a private good in first period and with nothing in second period of life. Each generation can access a storage technology with a gross return rate of $R>0$. If a generation invests one unit of a private good in first period, then it can gain $R$ units in second period. Hence, the budget constraint of generation $t$ in first period is

$$
w_{t}=c_{t}^{1}+s_{t}+m_{t}
$$

and in second period is

$$
c_{t+1}^{2}=R s_{t}
$$

where $s_{t}$ is the amount of investment in a storage technology.

These constraints are summarized as the life-cycle budget constraint:

$$
c_{t}^{1}+c_{t+1}^{2} / R+m_{t}=w_{t}
$$

\section{The optimization problem}

The agent chooses $\left\{c_{t}^{1}, c_{t+1}^{2}, s_{t}, m_{t}\right\}$ to maximize his utility (7) subject to (11) and (8). The first-order conditions which express the outcome of generation $t$ are

$$
\begin{aligned}
& (1-0.5 \gamma / L)\left[(1-0.5 \gamma) c_{t}^{1}-0.5 \gamma c_{t}^{2}\right]^{-\varepsilon}=(\delta+\beta) E_{t+1}{ }^{-\varepsilon} \\
& (1-0.5 \gamma / L) R\left[-0.5 \gamma c_{t+1}^{1}+(1-0.5 \gamma) c_{t+1}^{2}\right]^{-\varepsilon}=\delta E_{t+1}{ }^{-\varepsilon}
\end{aligned}
$$

Equation (12) indicates that generation $t$ chooses consumption when young, equating the marginal rate of substitution between consumption in youth and environmental quality in old age to the marginal rate of transformation, $(\delta+\beta) /(1-0.5 \gamma / L)$. At the utility maximum, a decrease in utility due to falling consumption during youth is equal to an increase in utility due to the sum of an increase in maintenance effort, $\delta /(1-0.5 \gamma / L)$, and a decrease in a consumption externality, $\beta /(1-0.5 \gamma / L)$.

Equation (13) shows that generation $t$ chooses savings, equating the marginal rate of substitution between the effective consumption in old age, $\left[-0.5 \gamma c_{t+1}^{1}+(1-0.5 \gamma) c_{t+1}^{2}\right]$, andenvironmental quality in old age to the marginal rate of transformation, $\delta /(1-0.5 \gamma / L) R$. At the utility maximum, a decrease in utility due to falling consumption during old age,(1$0.5 \gamma / L) R$, is equal to an increase in utility due to an increase in maintenance effort, $\delta$. 


\section{Steady state}

A steady state equilibrium is an allocation such that $\left\{c^{1}, c^{2}, m, E\right\}$ is stationary along the equilibrium path. Particularly, the steady state equilibrium levels of consumption and environmental quality $\left\{c^{1}, c^{2}, E\right\}$ are characterized by the following three equations:

$$
\begin{gathered}
(1-0.5 \gamma / L)\left[(1-0.5 \gamma) c^{1}-0.5 \gamma c^{2}\right]^{-\varepsilon}=(\delta+\beta) E^{-\varepsilon} \\
(1-0.5 \gamma / L) R\left[-0.5 \gamma c^{1}+(1-0.5 \gamma) c^{2}\right]^{-\varepsilon}=\delta E^{-\varepsilon} \\
\beta L\left(c^{1}+c^{2}\right)=\delta L\left(w-c^{1}-\frac{c^{2}}{R}\right)
\end{gathered}
$$

Equations (14), (15) and (16) lead to the existence and uniqueness of the steady state equilibrium. The next section depicts the analysis carried on at this steady state.

\section{The impacts of outward habits on environmental quality}

This section studies how outward habitinfluences the steady state equilibrium level of environmental quality, afterward discusses the consequences of the result for an economy under outward habit.

The differentiation of (14), (15) and (16) with respect to $c^{1}, c^{2}, E$ and $\gamma$ taking $\beta, \delta$ and $R$ as given yields

$$
\begin{aligned}
& {\left[\begin{array}{ccc}
-(1-0.5 \gamma / L)(1-0.5 \gamma) \varepsilon\left(\tilde{c}^{1}\right)^{-\varepsilon-1} & 0.5 \gamma(1-0.5 \gamma / L) \varepsilon\left(\tilde{c}^{1}\right)^{-\varepsilon-1} & (\delta+\beta) \varepsilon E^{-\varepsilon-1} \\
0.5 \gamma(1-0.5 \gamma / L) R \varepsilon\left(\tilde{c}^{2}\right)^{-\varepsilon-1} & -(1-0.5 \gamma / L)(1-0.5 \gamma) R \varepsilon\left(\tilde{c}^{2}\right)^{-\varepsilon-1} & \delta \varepsilon E^{-\varepsilon-1} \\
L(\delta+\beta) & L\left(\frac{\delta}{R}+\beta\right) & 0
\end{array}\right]\left[\begin{array}{c}
\partial c^{1} \\
\partial c^{2} \\
\partial E
\end{array}\right]} \\
& =\left[\begin{array}{c}
0.5\left[1 / L\left(\tilde{c}^{1}\right)^{-\varepsilon}-(1-0.5 \gamma / L)\left(c^{1}+c^{2}\right) \varepsilon\left(\tilde{c}^{1}\right)^{-\varepsilon-1}\right] \\
0.5 R\left[1 / L\left(\tilde{c}^{2}\right)^{-\varepsilon}-(1-0.5 \gamma / L)\left(c^{1}+c^{2}\right) \varepsilon\left(\tilde{c}^{2}\right)^{-\varepsilon-1}\right]
\end{array}\right] \partial \gamma \\
& 0
\end{aligned}
$$

It is directly shown that the determinant of the left-hand side matrix is positive. Let $|D|$ represent the determinant. The conditions of the equilibrium characterize three equations system with three unknowns. That's why; the rank of this system must be equal to 3. Thus, the determinant $|D|$ must be different of 0 . The equilibrium condition system is then a Cramer's system. We proceed to the resolution of this system by Cramer's rule;

$$
\frac{\partial E}{\partial \gamma}=\frac{0.5(1-0.5 \gamma / L) R\left(2 \beta+\delta+\frac{\delta}{R}\right) \varepsilon}{|D|\left(\tilde{c}^{1}\right)^{\varepsilon}\left(\tilde{c}^{2}\right)^{\varepsilon+1}}\left[-L(1-0.5 \gamma / L)\left(c^{1}+c^{2}\right) \varepsilon\left(\tilde{c}^{1}\right)^{-1}+1\right]
$$


Proposition: Outward habit ameliorates (lowers) environmental quality if and only if $\lessgtr \Psi(\gamma)$ where

$$
\Psi(\gamma)=\frac{\tilde{c}^{1}}{L(1-0.5 \gamma / L)\left(c^{1}+c^{2}\right)}
$$

That is, $\partial E / \partial \gamma \gtrless 0$ if and only if $\varepsilon \lessgtr \Psi(\gamma) \forall \gamma \geq 0$.

Figure 1 illustrates the relation between $\varepsilon$ and $\Psi(\gamma)$. The function $\Psi(\gamma)$ is strictly decreasing and strictly convex in $\gamma$ with $\lim _{\gamma \rightarrow 0} \Psi(\gamma)=c^{1} / L\left(c^{1}+c^{2}\right)$ and $\lim _{\gamma \rightarrow \alpha} \Psi(\gamma)=0$. If $\varepsilon \geq$ $c^{1} / L\left(c^{1}+c^{2}\right)$, then $\partial E / \partial \gamma<0 \forall \gamma \geq 0$; that is, outward habitis always damaging the environment. On the other hand, if $\varepsilon<c^{1} / L\left(c^{1}+c^{2}\right)$, the initial value of $\gamma$ is crucial in determining the effect of outward habit on the environment. Given $\varepsilon$, there exists a critical level of $\gamma, \bar{\gamma}(\varepsilon)$, such that $\partial E / \partial \gamma \gtrless 0$ if and only if $\gamma \gtrless \bar{\gamma}(\varepsilon)$.

When the inequality $\varepsilon \geq c^{1} / L\left(c^{1}+c^{2}\right)$ holds, that is; $\varepsilon \geq c^{1} / 2 L C$, outward habit is always damaging the environment. This inequality necessitates a large cohort size $L$, given $C$ and $\varepsilon$. When $\varepsilon<c^{1} / L\left(c^{1}+c^{2}\right)$, the initial degree of outward habit plays an important role in determining the impact. We can estimate the impact by using the condition $\varepsilon \lessgtr \Psi(\gamma)$, which is rewritten as $\gamma \gtrless \bar{\gamma}(\varepsilon)$ where $\bar{\gamma}(\varepsilon)$ satisfies $\varepsilon=\Psi(\gamma)$. When the initial value of $\gamma$ is lower than the critical level $\bar{\gamma}(\varepsilon)$, a marginal rise in $\gamma$ has an intense impact on the environment; consequently, a greater strength of outward habitresults in a lower environmental quality. On the other hand, when the initial value of $\gamma$ is higher than the critical level, a marginal rise in $\gamma$ has an insignificant impact on the environment; consequently, a greater intensity of outward habit results in a higher environmental quality.

The result implies that when $\varepsilon<c^{1} / L\left(c^{1}+c^{2}\right)$ holds, there exists another critical level of the degree of outward habit, $\bar{\gamma}(\varepsilon)(>\bar{\gamma}(\varepsilon))$, such that $\left.\left.E\right|_{\gamma=0} \gtrless E\right|_{\gamma>0}$ holds if and only if $\gamma \lessgtr$ $\bar{\gamma}(\varepsilon)$ (see Figure 2). Explicitly, if the initial degree of outward habit $\gamma$ is larger (less) than the critical level $\overline{\bar{\gamma}}(\varepsilon)$, then the environmental quality without outward habit, $\left.E\right|_{\gamma=0}$, is less (larger) than the environmental quality under the presence of outward habit, $\left.E\right|_{\gamma>0}$. For a larger (smaller) degree of outward habit, the economy undergoes a greater (lesser) environmental quality relative to the economy without outward habit. Consequently, striving to improve social position via consumption is not necessarily damaging the environment. A higher strength of outward habit may be advantageous from the perspective of environmental protection.

\section{Figure 1}

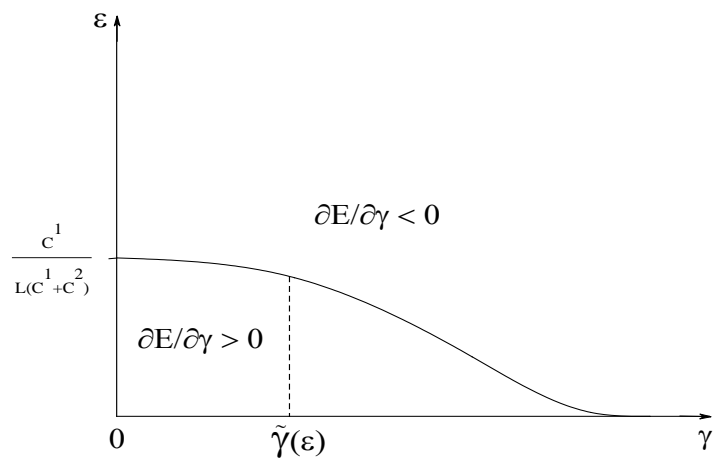


Figure 2

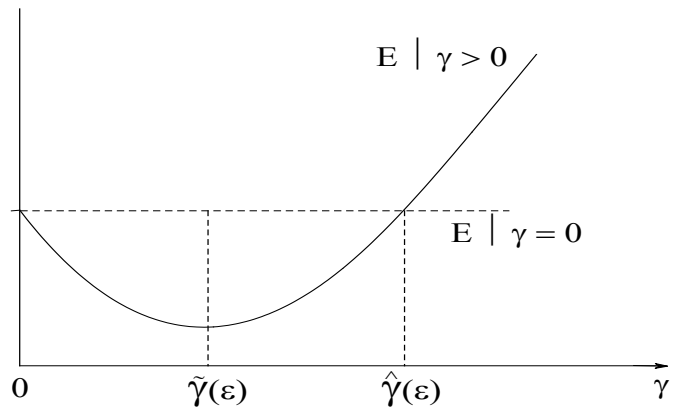

\section{Conclusion}

In this paper, we have extended the overlapping generations literature by introducing outward habits in a model with environmental quality and maintenance spending. We found that whether outward habits are damaging the environment depends on the degrees of status seeking and the size of the economy. Hence, this paper has given a simple condition for evaluating environmental consequence of outward habit. Indeed, numerous researches focused only on intergenerational externalities resulting from consumption, cutting out the free-rider problem. The impacts within a generation have been largely disregarded by the OLG literature. Several works normalize the size of each cohort as unity. Thereby, the intragenerational impacts are not taken into consideration in the framework of the model. This analysis rather takes into consideration both the intra- and the intergenerational negative impacts of consumption. At this stage of analysis, we would assert that this work is a step that may be taken further, extended and hilt upon as it lays the ground and pave the way for future research to enact the inclusion of population growth which might provide new insights on the role of population in such a framework.

\section{References}

Allais, M., 1947. Economie et Interet. Paris: Imprimerie Nationale.

Aronsson, T., and Johansson-Stenman, O., 2014. State-variable public goods and social comparisons. Journal of Environmental Economics and Management, 68 (2), pp. 390-410. https://doi.org/10.1016/j.jeem.2014.07.001.

Becker, G. S., 1992. Habits, addictions, and traditions. Kyklos, 45 (3), pp. 327-345. https://doi.org/10.1111/j.1467-6435.1992.tb02119.x.

Bouché, S., 2017. Aspirations, environmental quality and optimal tax policy. ECOBAS working papers, 2016-21. https://doi.org/10.13140/RG.2.2.10514.66247.

Bouché, S., and de Migel, C., 2019a. Optimal fiscal policy in a model with inherited aspirations and habit formation. Journal of Public Economic Theory, 21 (6), pp. 1309-1331. https://doi.org/10.1111/jpet.12385.

Bouché, S., and de Migel, C., 2019b. Endogenous aspirations, growth and the rise of environmental concerns. Energy Economics, 84, 104526. https://doi.org/10.1016/j.eneco.2019.104526.

Brekke, K, Howarth R.B., and Nyborg, K., 2002. Status-seeking and material affluence: evaluating the Hirsch hypothesis. Ecological Economics, 45, pp. 29-39. https://doi.org/10.1016/S0921-8009(02)00262-8. 
Clark, A. E. and Oswald, A. J., 1996. Satisfaction and comparison income, Journal of Public Economics, 61 (3), pp. 359-381. https://doi.org/10.1016/0047-2727(95)01564-7.

de la Croix, D., 1996. The dynamics of bequeathed tastes. Economics Letters, 53, pp. 89-96. https://doi.org/10.1016/S0165-1765(96)00888-9.

de la Croix, D., and Michel, P., 1998. Optimal growth when tastes are inherited. Journal of Economic Dynamics and Control, 23, pp. 519-537. https://doi.org/10.1016/S0165-1889(98)00028-1

Diamond, P. A., 1965. National debt in a neoclassical growth model, American Economic Review, 55(5), 1126-1150. Retrieved December 10, 2020, from http://www.jstor.org/stable/1809231

Ek, K., and Söderholm, P., 2008. Norms and economic motivation in the Swedish green electricity market. Ecological Economics, 68, pp. 169-182. https://doi.org/10.1016/j.ecolecon.2008.02.013

Ferrer-iCarbonell, A., 2005. Income and well-being: an empirical analysis of the comparison income effect. Journal of Public Economics, 89 (5), pp. 997-1019. https://doi.org/10.1016/j.jpubeco.2004.06.003

Hirsch, F., 1976. The social limits to growth. Cambridge: Harvard University Press,. Howarth, R.B., 1996. Status effects and environmental externalities. Ecological Economics,16, pp. 25-34. https://doi.org/10.1016/0921-8009(95)00076-3

Howarth, R.B., 2006. Optimal environmental taxes under relative consumption effects. Ecological Economics, 58, pp. 209-219. https://doi.org/10.1016/j.ecolecon.2005.07.007.

John A., and Pecchenino, R., 1994. An overlapping generations model of growth and the environment. The Economic Journal, 104, 1393-1410. https://doi.org/10.2307/2235455. Jouvet, P.A., 1998. Voluntary contributions with uncertainty: the environmental quality. CORE Discussion Paper 1998020, Université Catholique de Louvain. https://doi.org/10.1023/A:1008678228249

Katayama, S., and Long, N. V., 2010. A dynamic game of status-seeking with public capital and an exhaustible resource, Optimal Control Applications and Methods, 31, pp. 43-53. https://doi.org/10.1002/oca.877

Long, N. V. and Wang, S., 2009. Resource grabbing by status-conscious agents. Journal of Development Economics, 89 (1), pp. 39-50. https://doi.org/10.1016/j.jdeveco.2008.09.005. Ono, T., and Maeda, Y., 2001. Is aging harmful to the environment? Environmental and Resource Economics, 20 (2), pp. 113-127. https://doi.org/10.1023/A:1012676227797.

Rauscher, M., 2006. Voluntary emission reductions, social rewards, and environmental policy. CESifo Working Paper No. 1838, Munich.

Wendner, R., 2003. Status, environmental externality, and optimal tax programs. Economics Bulletin, 8 (5), pp. 1-10. Available at SSRN:https://ssrn.com/abstract=689782. Wendner R., 2005. Frames of reference, the environment, and efficient taxation. Economics of Governance, 6 (1), pp. 13-31. https://doi.org/10.1007/s10101-004-0086-6.

\section{Bionote}

Fatma Safi is a researcher at the Faculty of Economics and Management of Sfax, Tunisia. She has a Ph.D. in Economics at University of Sfax. Her main interests refer to environmental economics and social preferences. 